\title{
Corrigendum: Prefrontal and striatal dopaminergic genes predict individual differences in exploration and exploitation
}

Michael J Frank, Bradley B Doll, Jen Oas-Terpstra \& Francisco Moreno

Nat. Neurosci. 12, 1062-1068 (2009); published online 20 July 2009; corrected after print 9 September 2009

In the version of this article initially published, the last sentence of the second paragraph in the right column on page 1065 read "that is, the following term was added to the RT prediction: $\rho\left[\sigma_{\text {slow }}(s, t)-\sigma_{\text {fast }}(s, t)\right]$, where $\rho$ is a free parameter." A variable in the equation contained in this sentence was incorrect. The sentence should read "that is, the following term was added to the RT prediction: $\rho\left[\mu_{\text {slow }}(s, t)-\mu_{\text {fast }}(s, t)\right]$, where $\rho$ is a free parameter." The error has been corrected in the HTML and PDF versions of the article.

\section{Corrigendum: $\mathrm{Ca}^{2+}$ and calmodulin initiate all forms of endocytosis during depolarization at a nerve terminal}

Xin-Sheng Wu, Benjamin D McNeil, Jianhua Xu, Junmei Fan, Lei Xue, Ernestina Melicoff, Roberto Adachi, Li Bai \& Ling-Gang Wu Nat. Neurosci. 12, 1003-1010 (2009); published online 26 July 2009; corrected after print 3 September 2009

In the version of this article initially published, the units for the calcium concentration labels in Figure $2 \mathrm{a}$, $\mathrm{d}$ are incorrect. The correct unit should be $\mu \mathrm{M}$. The error has been corrected in the HTML and PDF versions of the article.

\section{Corrigendum: AP2 $\gamma$ regulates basal progenitor fate in a region- and layer-specific manner in the developing cortex}

\begin{abstract}
Luisa Pinto, Daniela Drechsel, Marie-Theres Schmid, Jovica Ninkovic, Martin Irmler, Monika S Brill, Laura Restani, Laura Gianfranceschi, Chiara Cerri, Susanne N Weber, Victor Tarabykin, Kristin Baer, François Guillemot, Johannes Beckers, Nada Zecevic, Colette Dehay, Matteo Caleo, Hubert Schorle \& Magdalena Götz Nat. Neurosci. 12, 1229-1237 (2009); published online 13 September 2009; corrected after print 25 September 2009.
\end{abstract}

In the version of this article initially published, one of the corresponding authors' email addresses was misspelled. It should be luisapinto@ecsaude. uminho.pt. In addition, errors occurred in some of the numbers listed in the last subsection of the Results section. Instead of "Notably, AP2 $\gamma^{-/-}$mice also showed alterations in cortical binocularity (Fig. 7c,d and Supplementary Table 2) and a tendency toward an increased latency of visual response ( wild type $=109.95 \mathrm{~ms}, A P 2 \gamma^{-/-}=127.19 \mathrm{~ms}$; Supplementary Table 2). [...] Indeed, monocular deprivation for $3 \mathrm{~d}$ caused a significant change in binocularity in adult $A P 2 \gamma^{-/-}(P=0.027)$, but not wild-type $(P=0.365)$, mice (Fig. 7d)," the affected sentences should read, "Notably, $A P 2 \gamma^{-1-}$ mice also showed alterations in cortical binocularity (Fig. 7c,d and Supplementary Table 2) and a tendency toward an increased latency of visual response (wild type $=110.0 \pm 3.8 \mathrm{~ms}, A P 2 \gamma^{-l-}=127.2 \pm 6.4 \mathrm{~ms}$; $t$-test, $P=0.05$; Supplementary Table 2). [...] Indeed, monocular deprivation for 3 d caused a significant change in binocularity in adult $A P 2 \gamma^{-1-}(P=0.01)$, but not wild-type $(P=0.365)$, mice $($ Fig. 7d)." The errors have been corrected in the HTML and PDF versions of the article.

\section{Erratum: Adult generation of glutamatergic olfactory bulb interneurons}

Monika S Brill, Jovica Ninkovic, Eleanor Winpenny, Rebecca D Hodge, Ilknur Ozen, Roderick Yang, Alexandra Lepier, Sergio Gascón, Ferenc Erdelyi, Gabor Szabo, Carlos Parras, Francois Guillemot, Michael Frotscher, Benedikt Berninger, Robert F Hevner, Olivier Raineteau \& Magdalena Götz

Nat. Neurosci. 12, 1524-1533 (2009); published online 1 November 2009; corrected after print 11 December 2009

In the version of this article initially published, the email address of one of the corresponding authors was misspelled. It should be magdalena.goetz@helmholtz-muenchen.de. The error has been corrected in the HTML and PDF versions of the article.

\section{Erratum: Dynamic DNA methylation programs persistent adverse effects of early-life stress}

Chris Murgatroyd, Alexandre V Patchev, Yonghe Wu, Vincenzo Micale, Yvonne Bockmühl, Dieter Fischer, Florian Holsboer, Carsten T Wotjak, Osborne F X Almeida \& Dietmar Spengler

Nat. Neurosci. 12, 1559-1566 (2009); published online 8 November 2009; corrected after print 3 December 2009

In the version of this article initially published, on page 2, left column, the phrase "....and typically cluster in glucocorticoid-rich regions called CpG islands (CGIs)" should be “... and typically cluster in GC-rich regions called CpG islands (CGIs)". The error has been corrected in the HTML and PDF versions of the article. 